\title{
[Re]buscando el amor: \\ Motivos y razones de las uniones mixtas de hombres españoles con mujeres extranjeras
}

\author{
[Re]Looking for Love: \\ Motives and Reasons for Mixed Unions of Spanish \\ Men with Foreign Women
}

\author{
Jordi Roca Girona \\ Departamen d'Antropologia, Filosofia i Treball Social \\ Universitat Rovira i Virgili. Tarragona
}

\section{RESUMEN}

El artículo aborda el fenómeno reciente y creciente de las uniones sentimentales mixtas. Se centra en parejas heterosexuales compuestas por un hombre español y una mujer extranjera de origen latinoamericano o eslavo, las predominantes en España. La hipótesis de partida vincula el fenómeno a las transformaciones acaecidas en el sistema de género en España y lo contextualiza en el nuevo orden mundial caracterizado por el aumento y la facilidad de la movilidad y la comunicación. La atención se focaliza en las motivaciones expresadas por los diversos actores sociales implicados en estas uniones.

Palabras clave: Matrimonios mixtos, Selección de pareja, Transformaciones de género.

\section{SUMMARY}

The paper addresses the recent and growing phenomenon of mixed sentimental unions. It centers on heterosexual couples integrated by a Spanish man and a foreign woman of Latin American or Slavic origin, wich are the predominant in Spain. The initial hypothesis relates this phenomenon to transformations in the gender system in Spain, and contextualizes it in the new global order, characterized by the increase and facility for communication and mobility. Attention is drawn to the motivations expressed by the social actors involved in these unions.

Key words: Mixed Marriages, Partner Selection, Gender Transformations. 


\section{INTRODUCCIÓN: CUESTIONANDO EL SENTIDO COMÚN}

¿Por qué Josep Maria (y miles de hombres españoles más ${ }^{1}$ ), un ingeniero de 56 años, culto y educado, casado y divorciado dos veces decidió, un día del año 2002, suscribirse a una agencia de Internet con el fin de relacionarse con una comunidad potencial de miles de mujeres de países lejanos que desean encontrar esposo en Europa y Estados Unidos principalmente?

¿Cuál es la razón — o razones - por la que Tania, una joven rusa de 25 años, estudiante y divorciada, aceptara comunicarse con Josep M., 31 años mayor y, tras un noviazgo virtual, breve e intenso, acabara uniéndose a él en pareja?

La respuesta que encontré en los medios de comunicación y en la opinión pública en general ofrecía un paquete compuesto de dos estereotipos ${ }^{2}$ distintos pero interconectados que parecía no ofrecer ningún género de dudas: Josep M., y miles de hombres como él, estaría buscando una combinación de esclava sexual y sirvienta doméstica, mientras que Tania, y miles de mujeres como ella, iría a la caza de alguien que la sacara de la miseria y le ofreciera unas mejores condiciones de vida a ella y, tal vez también, a su familia, que le permitiera, en definitiva, obtener "los papeles", como acostumbra a expresarse coloquial y metafóricamente. La rotundidad argumental, sin fisuras, de estas fuentes se completaba con una actitud de perplejidad y conmiseración hacia mí cuando quienes las emitían formaban parte, además, de mi entorno y debían asistir a mis tímidos intentos de considerar un espectro más amplio de motivos, razones y expectativas.

Las respuestas que encontré más adelante ${ }^{3}$, después de dialogar con decenas de personas integrantes de estas uniones y con algunos de sus fa-

${ }^{1} 151.190$ fue el total de hombres españoles que se casaron con una mujer extranjera en el período 1996-2009, frente a las 103.440 mujeres españolas que hicieron lo propio con un hombre extranjero (Fuente: INE, elaboración propia).

${ }^{2}$ En el sentido de generalizaciones simplificadas, que toman uno o muy pocos aspectos de la realidad, compartidas socialmente, acerca de un grupo o fenómeno social.

${ }^{3}$ Los datos de este artículo provienen del Proyecto "Amor importado, migrantes por amor: la constitución de parejas entre españoles y mujeres de América latina y de Europa del Este en el marco de la transformación actual del sistema de género en España”, Proyectos de Investigación Científica y Desarrollo Tecnológico. Programa: Acción Estratégica sobre Fomento de Igualdad de Oportunidades entre mujeres y hombres. Plan $\mathrm{Na}$ cional de I+D+I (2004-2007), Ministerio de Trabajo y Asuntos Sociales, Instituto de la Mujer. Formaron parte activa del mismo: Lídia Martínez, Yolanda Bodoque, Montserrat Soronellas y Marija Djurdjevich. En estos momentos hemos iniciado otro proyecto como continuación y ampliación del mismo: "Amores transnacionales: constitución y desarrollo de parejas mixtas en España”. Plan Nacional de I+D+I (2008-2011), Ministerio de Ciencia e Innovación (CSO2009-10187). 
miliares, con profesionales de agencias matrimoniales y con los textos de los pocos colegas que en su día se hicieron también preguntas similares a las mías y persistieron en el intento de hallar explicaciones que fueran más allá de las atribuibles al llamado sentido común, me permitieron constatar la variedad, complejidad y heterogeneidad de motivos, procesos, contextos y experiencias presentes en el fenómeno emergente de las denominadas parejas, uniones o matrimonios mixtos o binacionales.

\section{METODOlOGía: BUSCANDO LA TEXTURA DE LAS VIDAS}

Dado que las cuestiones, o preguntas de investigación, que alimentaron desde el inicio el trabajo focalizaban la atención en aspectos relativos a las motivaciones sobre la elección de un determinado tipo de pareja y en el itinerario consiguiente de la búsqueda, el encuentro, el proceso de conocimiento, la decisión de formalizar la unión y la experiencia de la vida en común, se incorporó una perspectiva cualitativa tanto de obtención como de análisis de unos datos de naturaleza fundamentalmente descriptiva.

A lo largo del año 2007 se realizaron un total de 65 entrevistas en profundidad, principalmente a miembros de parejas mixtas heterosexuales formadas por hombre español y mujer extranjera, con un total de 71 informantes - hubo 6 entrevistas de carácter doble, a ambos miembros de la pareja a la vez, siendo el resto de carácter individual—, fundamentalmente hombres españoles -19 en total- y mujeres eslavas (ucranianas y rusas principalmente -19 entre ambas_-) y latinoamericanas (15 informantes en total, cerca de la mitad brasileñas) ${ }^{4}$. Se entrevistó, también, a cuatro responsables de agencias matrimoniales, un abogado, una directora de una revista dirigida a la comunidad rusa-ucraniana española y un familiar de un hombre español perteneciente a una pareja mixta. Las entrevistas fueron de larga duración - entre una y tres horas - y casi todas cara a cara, excepto dos que se realizaron por chat y correo electrónico y por teléfono. En tres entrevistas, con mujeres ucranianas, se precisó de traductor. Estas entrevistas, junto a otras 12 más, se llevaron a cabo en Kiev en junio de 2007, en el marco de una

\footnotetext{
${ }^{4}$ Dos de cada tres matrimonios entre hombre español y mujer extranjera son con una mujer americana y, más concretamente, en su mayoría, perteneciente a algún país latinoamericano. Los matrimonios con mujeres europeas se sitúan en segundo lugar, representando alrededor de un tercio de los anteriores. En términos de representatividad estadística, el perfil de unión mixta mayoritaria en España es el de hombre español y mujer brasileña y hombre español y mujer rusa. Para un tratamiento más amplio y profundo sobre la distribución geográfica de los matrimonios mixtos españoles véase Roca et al (2009) y Roca (2009).
} 
breve estancia de campo como observador participante de uno de los numerosos viajes organizados por diversas agencias matrimoniales especializadas.

MARCO TEÓRICO: LAS RUTAS GLOBALES DE BÚSQUEDA DE CÓNYUGE Y LAS TRANSFORMACIONES DEL GÉNERO Y EL AMOR

En la literatura especializada sobre uniones mixtas se constata un predominio de trabajos que se centran en los principales itinerarios que recogen los flujos de cónyuges y parejas, así como la dirección y el sentido de los mismos. La búsqueda global de cónyuge, en este sentido, dibuja unas rutas - prácticamente idénticas o muy parecidas, por lo demás, a las del llamado turismo sexual, no en vano la industria de las llamadas mail order brides o esposas a pedido es presentada a menudo como un microcosmos de la más amplia industria internacional del sexo- que van de los países ricos del occidente europeo, Norteamérica y Asia-Pacífico a regiones del Caribe, Latinoamérica, el este de Europa y el sudeste asiático (véanse, entre otros, Cahill 1990; Cooke 1986; Suzuki 2003; Mainardi 2006; Riaño 2003; Chin 1994; Cohen 1986; Halualani 1995; Robinson 1996; De Melo 2000; Bermúdez 2007). También existen trabajos de carácter más general que abordan el fenómeno desde diversas perspectivas (Barbara 1985; Constable 1998, 2003; Clark 2001; Delcroix y Guyaux 1992; Ordóñez 1997; Roca et al. 2009; Scholes 1999; Simons 1999; Riaño y Baghdadi 2007). Las principales aportaciones de estas investigaciones residen en el hecho de describir los diversos patrones de género vinculados a la movilidad marital en un contexto global, ilustrando cómo algunas mujeres gozan de oportunidades de movilidad no disponibles para los hombres, debido a particulares geografías del poder atravesadas de forma determinante por la variable del género. También se muestra, en este sentido, cómo algunos hombres y mujeres tienen la habilidad para decidir su propia movilidad y la de otros. Las investigaciones recientes han hecho hincapié, igualmente, en los nuevos patrones de mercantilización y el crecimiento de los negocios vinculados a la búsqueda de pareja transnacional, en lo que bien podríamos denominar un "supermercado matrimonial global" (véanse Johnson 2007; Johnson-Hanks 2007; Constable 1998, 2003; Piper y Roces 2003; Thai 2008; Wang y Chang 2002). Los estudios, en fin, abordan los nuevos patrones de movilidad de personas de las distintas clases sociales, los costes y beneficios de la salida o la permanencia en el país, las motivaciones y razones para la salida, el papel de las nuevas tecnologías en estos procesos, así como la incidencia de estas uniones sobre el concepto de amor (Gamburd 2000; Parreñas 2005). 
Nuestro trabajo, por tanto, constituye una aportación a esta emergente literatura, permitiendo el conocimiento de las características que adoptan en España buena parte de las cuestiones que se han presentado hasta aquí en estudios centrados en otros países. El hecho de que España sea un país de reciente protagonismo como receptor de migrantes - a diferencia de la mayoría de países en los que ha sido analizado este fenómeno- y que en los últimos años se haya convertido en el país de la Unión Europea con un mayor número de matrimonios mixtos y el mayor porcentaje de extranjeros, hacen si cabe más pertinente aún nuestra aportación. España se ha significado también como uno de los países en donde se ha producido una notable transformación en el sistema de género en las últimas décadas, con cambios sociológicos de cierta consideración (incorporación de la mujer a los niveles superiores de formación y al mercado de trabajo y mayor capacidad de control y emancipación de su papel como reproductora) y políticas de género, especialmente y fundamentalmente legislativas, a menudo de carácter pionero y muy publicitadas, tanto dentro como fuera de sus fronteras (matrimonio homosexual, leyes recientes del aborto y del divorcio que amplían supuestos y agilizan procesos). Este extremo, precisamente, alimentó una de nuestras hipótesis de partida, centrada en el hecho de que la mayor independencia material y sentimental adquirida por las mujeres españolas como consecuencia de los cambios señalados estaría ocasionando como resultado la resistencia de algunos hombres que, en desacuerdo con este nuevo y cada vez más generalizado modelo femenino, se habrían lanzado a buscar pareja en un mercado matrimonial distinto al del propio país, en el marco de lo que ha venido a denominarse en los últimos años "crisis de la masculinidad" 5

Este contexto estatal que hemos esbozado para la ubicación del fenómeno estudiado debe integrarse, asimismo, en un marco supranacional caracterizado por la creciente existencia de flujos transnacionales y realidades de carácter globalizado, por la emergencia y extensión de las nuevas tecnologías de la información y la comunicación (TIC) y por el paso de una sociedad centrada en la producción a otra centrada en el consumo y en la elección. Esto nos sitúa en un escenario en donde los límites y las fronteras entre migración y movilidad se difuminan al tiempo que crece su intensidad en relación a recursos de toda índole: personas, capitales, mercancías (Featherstone 1990; Robertson 1992; Hannerz 1998; Appadurai 2001). La movilidad electrónica característica de la sociedad de la información hace posible que cualquier lugar del mundo sea susceptible de estar cerca o de

\footnotetext{
${ }^{5}$ Véase, con carácter general, MacInnes (1998); Mac an Ghaill (1996) y Seidler (2006); y para el caso español Gil Calvo (1997).
} 
ser accesible con carácter inmediato. Estas tecnologías, además, favorecen la existencia de la llamada sociedad de consumo o, mejor, de consumidores (Featherstone 1991; García Canclini 1995). Un elemento idiosincrásico de ésta lo constituye la oferta constante y variada de productos y servicios -y la correspondiente creación de necesidades de adquirirlos y consumirlos- que consolida el ejercicio de la elección, en todos los ámbitos de la vida, como el acto de máxima expresión de un yo postmoderno (Beck et al. 1994; Giddens 2000b) construido sobre bases eclécticas y carentes de verdades únicas (Bauman 1992).

La incidencia de estas nuevas realidades contextuales en el territorio amoroso es también constatable. La eclosión del amor romántico estableció un nuevo patrón que vinculó al matrimonio la pasión y la durabilidad sobre la base del principio de la libertad de elección de la pareja (Thery 1998). Más adelante, ya en la segunda mitad del siglo pasado, en un contexto marcado por la denominada sociedad de consumo y por el influjo de la llamada planificación biográfica abierta o biografía elegida, el concepto de amor romántico irá siendo sustituido, en opinión de Giddens (2000a), por el de amor confluente: un amor contingente, activo, que se desembaraza de la eternidad - "para siempre" - y la exclusividad — "uno y solamente uno"propias del amor romántico, para fundarse en la reflexividad: las relaciones continúan porque así lo eligen ambos miembros de la pareja.

En suma, como han documentado diversos autores (Beck y BeckGernsheim 1998; Shumway 2003; Zelizer 2005), muchos aspectos de la intimidad y de las relaciones personales han ido comercializándose cada vez más explícitamente vinculados a los procesos globales de mercantilización o bajo la presión de las "biografías de mercado" o vidas conformadas por las demandas del mercado.

¿POR QUÉ BUSCAR? ¿A QUIÉN BUSCAR? ¿PARA QUÉ BUSCAR?: RAZONES Y SINRAZONES DE LA BÚSQUEDA TRANSNACIONAL

Las razones que impulsan a buscar, desear o simplemente aceptar una pareja de una nacionalidad distinta a la propia parece compleja, por cuanto se abastece de elementos explícitos e implícitos, así como diversa, en función del lugar y la posición que ocupa quien habla. De forma esquemática, los hombres españoles acostumbran a situar en primer lugar las motivaciones de orden sentimental y de género (valorando de las mujeres latinas y eslavas su priorización de la familia y el hecho de ser cariñosas y dóciles) y en segunda posición — difuminándolas - las razones de carácter físico (la belleza y sensualidad de las citadas mujeres); en tanto que las mujeres lati- 
nas y eslavas, por su parte, posicionan las razones de género (búsqueda de relaciones de género más igualitarias y de un hombre respetuoso y fiel) en primera línea y, en un segundo lugar más evasivo, las de orden material (la mejora de su situación socioeconómica).

Esta variedad de consideraciones permite vislumbrar algunos extremos interesantes. Uno de ellos tiene que ver con la existencia de una situación aparentemente contradictoria y antitética que surgiría del hecho de que en tanto que el hombre español, en línea con una de nuestras hipótesis de partida, busca una mujer que bien podría calificarse como de perfil tradicional, las mujeres latinas y eslavas manifiestan querer encontrar a un hombre más igualitario que el que predomina en sus países, esto es, un "marido moderno". A esto puede añadírsele además, en ocasiones, el desequilibrio y la disparidad, que puede derivar en desencuentro y conflicto, entre la posición social y el nivel educativo de algunas esposas eslavas y latinas y sus maridos españoles de menor nivel, como han constatado también, en sus respectivos estudios de esposas chinas, filipinas y vietnamitas casadas transnacionalmente N. Constable (2003) y H. C. Thai (2008). La comparación que ambos, mujeres latinas y eslavas y hombres españoles, realizan constantemente con sus compatriotas del género opuesto, constituye una de las principales estrategias de justificación de la búsqueda correspondiente $y$, a su vez, de clarificación de algunos de los motivos fundamentales de la misma. No es extraño, pues, que los hombres españoles contrasten en sus discursos la imagen de las mujeres que buscan con la que tienen de las españolas, siendo así que las mujeres latinas y eslavas utilizan igualmente de forma reiterativa el recurso de comparar a sus compatriotas masculinos con los hombres europeos en general y españoles en particular. Ambos, además, incorporan a menudo la comparación contrastada con sus homólogos de género del país al que pertenecen sus parejas, destacándose la presencia de un cierto complejo de superioridad en relación a ellos.

En el fondo, pues, lo que acaba produciéndose es una suerte de equilibrio de polaridades, opuestas en términos de género y nacionales, pero coincidentes en su significación positiva: las "buenas" mujeres latinas (cariñosas, afectuosas, comprensivas) ${ }^{6}$ y eslavas (atentas, educadas) que deben soportar a los hombres "impresentables" (machistas, infieles, irresponsables, no comprometidos, alcohólicos, agresivos...) de sus países y los "buenos" hombres españoles (colaboradores, atentos) que deben soportar a las mujeres "maltratadoras" (frías, altivas, autoritarias) de su país hallan la mutua

\footnotetext{
${ }^{6}$ Los calificativos citados y los subsiguientes son los que emanan de forma mayoritaria de las entrevistas con los correspondientes actores sociales y de las páginas de las agencias matrimoniales especializadas.
} 
"salvación" formando una unión sentimental que además de juntar estas complicidades reúne también, compensándolos, elementos antagónicos (precariedad material contra precariedad afectiva), dándose pues algo así como una especie de "reciprocidad equilibrada", de acuerdo con el modelo de Sahlins (1977) que la presenta como el símbolo de la conversión de intereses diferentes en armónicos ${ }^{7}$. Esto, de algún modo, es lo que vienen a expresar Sonia (peruana, 35 años; casada con español, 37 años) y Jordi (español, 41 años; casado con venezolana, 37 años):

Yo he visto que acá existe el matriarcado, que la mujer adelante y el hombre... es lo que he podido observar. Y acá los hombres aguantan, los que yo he visto, no generalizo. Digo: mujeres un caso y hombres buenos. Las mujeres mandan mucho, gritan mucho, exigen mucho, tratan muy mal y ellos están ahí ayudando, haciendo... y yo digo: en mi país ya las hubiesen mandado los hombres a éstas por un tubo, digo yo. Me quedo pensando: ¿Cómo es? Y allá mujeres buenas, digo, y les tocan unos disparates, es al revés, digo, como no están valoradas ni nada. Allá, si fueran las de allá a acá estuvieran como unas reinas que las trataran, porque allá bueeeeeno, te mandan, te acaban, te acaban psicológica y emocionalmente, emocionalmente mayormente, te van acabando, te trabajan a lo psicológico [...] Yo soy democrática, yo aplico acá... ni tanto sometimiento, ni tanto mandamiento. Yo soy aquí democrática, porque yo veo a mis cuñados, las mujeres [pone voz de asustada]: "Ay, que tengo que ir..." Ellas mandonas cien por cien y todo lo que dicen y todo el rollo ${ }^{8}$, y ellos allí de buenos y varias parejas, y yo no, en cambio, como yo le dije a mi suegra, yo soy democrática, le digo, un poco para acá y un poco para allá (Sonia).

A la vez creo que el tema es una cuestión recíproca porque, claro, ¿qué es lo que la mujer de esa zona espera encontrar en un hombre? Así, grosso modo, un caballero, es decir, un hombre que la respete, que la trate con respeto y con cariño, que la cuide y que le dé atenciones y los cuidados que ella demanda, pero al tiempo de darle una posición y un respeto... Y, claro, eso es un ideal para

${ }^{7}$ Algo similar, en cierto modo, sucedería particularmente una vez que la pareja se ha constituido en una unión estable y se activan las estrategias de adaptación para hacer frente a los bagajes culturales distintos y, en ocasiones, divergentes de ambos miembros. Wimmer (1998) aplicó, al respecto, el concepto de "cultural compromise" en el marco de su investigación sobre matrimonios de mujeres suizas con hombres cubanos.

${ }^{8}$ Esta caracterización de las mujeres occidentales en general y españolas en particular como secas y autoritarias, en comparación y contraste con las mujeres latinoamericanas, la encontramos también en otras fuentes de índole diversa. Así, en una obra de un novelista cubano se lee: "Eso es lo maravilloso de la mujer cubana - debe haber muchas otras igual, tal vez en América, en Asia- es tan cariñosa que nunca puedes decir no cuando te piden algo. No es así con las europeas. Las europeas son tan secas que te dan todas las posibilidades para decirles ¡NO! Y quedarte a gusto”. (Pedro Juan Gutiérrez, Trilogía sucia de La Habana). En el curso de nuestra investigación vi una "pintada" en una pared del casco antiguo de Barcelona que decía: "Palabra preferida de las catalanas: ¡NO!”. 
una mujer de allí, encontrar un caballero... en contraposición al hombre macho que tienen allí que de alguna forma pues el respeto a la mujer pues está un poco por debajo [...]. Yo creo que este tipo de parejas, como es el caso nuestro, una de las cosas que lo facilita [...] es el hecho de la cuestión de la forma de ser de hombres y mujeres. A nosotros nos encaja muy bien este tipo de mujeres, al hombre, y a la mujer de allí le encaja muy bien este tipo de hombre. Entonces, claro, nos complementamos (Jordi).

Esta complementariedad y armonía de antagonismos, no obstante, parece resultar óptima y admisible hasta un cierto grado y no más allá de él, tal como se desprende de las palabras de Josep M.:

En cambio la gente del Este... ya había conocido otra chica y otras chicas que conocí ya hace unos años y las notaba mucho más asimiladas a nuestra cultura. En conceptos como seriedad, responsabilidad, manera de funcionar el cerebro, prioridades... lo encontré mucho más parecido a lo de aquí. Y en principio se está confirmando, quiero decir que no hay ninguna cosa rara ni extraña (Josep Maria, español 56 años; casado con rusa, 25 años) 9.

Natalia es una mujer de 48 años, nacida en San Petersburgo, con una hija de 27 años, que hace tiempo vino a España, se casó con un español viudo con tres hijos y montó una agencia matrimonial en 2001. Su mirada, asentada sobre el conocimiento de las numerosas parejas de españoles y rusas y ucranianas que ha contribuido a formar, enfatiza también la idea de reciprocidad equilibrada, aunque sin incorporar una comparación explícita con las contrapartes de género y nacionales de las parejas:

Los matrimonios, como yo veo, no son equilibrados, porque aunque parece, a lo mejor por fuera bastante bueno, por ejemplo un hombre de negocios, incluso un hombre bastante rico, pero no tiene ninguna formación porque su riqueza viene de familia, del negocio de la familia, y la mujer en este caso, normalmente, tiene mucha más formación, pero en el matrimonio, porque yo tengo muchos ejemplos de estos, el matrimonio compagina muy bien, porque el hombre le da la base, la seguridad, lo que busca la mujer, y la mujer es muy comprensiva, aprecia lo que le da y en este caso las mujeres por su parte tienen lo que buscan, porque la mentalidad de la mujer eslava, por lo menos la mayoría, somos muy familiares, nos gusta la familia y nos gusta la seguridad. El hombre que aprecia la mujer que quiere tener hijos, que quiere hacer la comida, que le gusta la cocina, le gusta el hogar en este aspecto aprecia y le da la base económica que necesitamos.

\footnotetext{
${ }^{9}$ En otro lugar (Roca et al. 2009) hemos mostrado cómo la búsqueda transnacional de amor posee una geografía de proximidad socio-cultural media en el caso de los hombres españoles, en tanto que para las mujeres españolas bascula mucho más hacia los extremos (cercanía y lejanía socio-cultural).
} 
La aproximación etnográfica, como hemos visto, nos aporta la consideración de razones y matices menos evidentes para la explicación y comprensión de estas uniones. En este sentido, las motivaciones y expectativas vinculadas a los sistemas de género de los países de pertenencia de hombres y mujeres, devienen centrales en los discursos de los actores sociales implicados.

La siguiente cita, correspondiente a Josep Maria, el hombre español de 56 años casado con una mujer rusa de 25 (uno de los perfiles de pareja mixta más estereotipado y estigmatizado socialmente por su acusada heterogamia de edad), con quien encabezábamos este artículo, sintetiza a la perfección la ya apuntada resistencia masculina a los avances femeninos como el deseo consecuente de buscar y establecer una relación sentimental de naturaleza similar a la que vivieron muchos hombres de la cohorte del informante en su primera experiencia de pareja con una mujer española, es decir, de signo claramente tradicional en términos de relaciones de género:

La mujer catalana [es] una mujer independiente, segura de sí misma, no necesitan al macho para casi nada, quiero decir que pueden hacer su vida perfectamente. Las de allí [Rusia], de alguna manera, quizá la palabra no es la correcta, pero aún tienen una cultura antigua de una pequeña devoción al macho. Entonces nosotros, yo, como soy un cobarde, y ya no me atrevo con las catalanas, porque es una lucha constante de si hacemos esto y demás, y yo de todo eso ya me cansé en mi tiempo y dije: ¡Basta! Entonces buscas una cosa, para tener una relación más fácil y que de alguna manera te traten un poco más así ¿no? Y más o menos objetivo cumplido por ahora (Josep María, español 56 años; casado con rusa, 25 años).

Jordi especifica un tanto más esa "cosa" buscada como consecuencia del rechazo o la resistencia a las mujeres españolas, ahondando en la retórica machista e incorporando además al colectivo de mujeres latinoamericanas, el principal polo de procedencia, junto a las mujeres de países eslavos, de las parejas mixtas de hombres españoles:

Y en principio pues sí, vi que las mujeres de allí... que su forma de ser coincide bastante con esa apreciación que uno tiene (cariñosas, sumisas).... Y además tienen una combinación muy interesante porque no sólo son cariñosas, suelen ser apasionadas, y me reitero en la cuestión, y... bueno, complacientes, mujeres muy al gusto de un hombre. Además tienen interés en cuidar la casa, no les importa realizar las tareas del hogar en un momento determinado. De alguna forma tienen una forma de ser... a mi gusto; encaja bien en mi circunstancia. Por ejemplo, Sol no está trabajando, bueno yo me puedo permitir que ella no trabaje, y, además consideramos que... no porque no quiera yo que trabaje, sino que consideramos que es lo mejor para el niño en los primeros años de su vida [...]. Porque la forma de ser que ellas tienen encaja muy bien en la que yo como hombre tengo. Eso no quita que a partir de una época ella se ponga a trabajar o estudie o haga 
lo que quiera, porque yo no tengo esa idea de que la mujer tenga que estar en casa. Ha de estar en casa cuando nos interesa que esté en casa, cuando queramos que no esté, no estará (Jordi, español, 41 años; casado con venezolana, 37 años).

Natalia, la ya conocida responsable de la agencia matrimonial, introduce una causa que no tiene que ver tanto con cuestiones relativas a la ideología de género, sino a consideraciones de tipo más material, incluso prosaico si se quiere:

Pues normalmente venimos cansadísimas de trabajar, porque por ejemplo, yo tengo 48 años, desde prácticamente los 17, 18, en paralelo con los estudios empecé a trabajar, entonces claro, ya con la época de la Perestroika que es cuando se nos puso muy difícil encontrar un trabajo, siempre con el temor de perderlo, entonces llegamos casi agotadas y ya no queremos trabajar, muchas mujeres lo tienen muy claro, incluso muy claro y lo ponen en sus fichas que "quiero tener hijos y dedicarme solamente a la educación de mis hijos, y de mi marido y del hogar, y no quiero trabajar fuera de casa", algunas que tienen buena formación y no tan buena, quieren trabajar como media jornada para no estar encerrada, para tener el contacto con la sociedad, con la gente.

Bien mirado, no obstante, el razonamiento en cuestión no se aleja demasiado de algunas posiciones surgidas entre algunos colectivos femeninos (notoriamente en el de las mujeres de clases medias-altas) en el post-feminismo de la igualdad como reacción a la aparición del fenómeno de la doble y triple jornada laboral.

Si bien hemos apuntado anteriormente que las expectativas de unos y otras podían fácilmente caer en una cierta contradicción, lo cierto es que las esposas extranjeras de hombres españoles con quienes hemos hablado no parecen desconocer en absoluto las motivaciones y expectativas en relación a ellas de sus esposos, si bien tal coincidencia no sabemos si se produce a posteriori, una vez constituida la pareja, o ya estaba presente en el momento anterior al inicio de la relación. Natalia, una joven rusa que no vino a España con la finalidad primaria de casarse, pero que ha tenido, y está buscando ahora mismo, un novio español, desarrolla un razonamiento que reproduce en primer lugar las razones escuchadas a los hombres españoles para, a continuación, hacerlas suyas:

Y yo le preguntaba: ¿Por qué os gusta tanto la mujer rusa? ¿Por qué no cubanas? "Primero, porque sois inteligentes, con vosotras se puede salir a la calle, o presentar a los amigos, que sois inteligentes y podéis dar una imagen que se puede presentar. Segundo, porque sois amas de casa, buenas cocineras, sabéis hacer bien al marido, cómodo ¿no? No calentar una comida, sino comida hecha por vosotras" y, luego dice: "que sois buenas en la cama. Buena presencia, inteligencia, casa, familia, hijos". Es su opinión, pero dice: "A vosotras al principio cuesta un 
poco llegar a una persona", primero frías y luego, cuando ya se rompe este hielo, ya no hay Dios que nos ${ }^{10}$ pare. Ya somos más calientes. Al principio sí, pero ya cuando ya está... [...] Los hombres de aquí necesitan cariño que le dan las mujeres de mi país, porque por ejemplo no recibieron tanto de mujeres de su país ¿vale? Que [las mujeres españolas] son un poquito más de trabajo, más de sus negocios, más de fuera que de casa. Nosotras somos más de casa que de fuera (Natalia, rusa, 25 años; soltera).

La cita de Natalia incorpora una dimensión que citábamos al principio que aparece generalmente como solapada, encubierta, en los discursos de los maridos españoles de mujeres extranjeras, razón por la cual no la encontramos en las afirmaciones de Josep M. y de Jordi: la belleza, la sensualidad, la sexualidad, la dimensión física y corporal, en suma. El hecho de que Natalia no pertenezca al colectivo de hombres españoles pertenecientes a parejas mixtas seguramente facilita la emergencia de este elemento. Otra Natalia, en este caso la responsable de agencia que ya hemos mencionado con anterioridad, también dedica una atención especial a la cuestión física, recuperando a su vez la metodología tan presente de la comparación entre personas del mismo género de distintas nacionalidades:

\begin{abstract}
¿Tú crees que los hombres españoles dan mucha importancia al aspecto físico?
Sí, sí, yo no esperaba tanto, viendo las mujeres [españolas] por las calles y con el aspecto que tienen! y no quiero ofender a nadie, yo nunca pensaba que el hombre español daba tanta importancia al aspecto físico de la mujer. Primero, nadie quiere a las mujeres gordas, entonces yo digo "icómo tenéis tantas gordas por las calles y mal vestidas!" Todos las quieren arregladas, vestidas y bien, con faldas, con faldas y no con pantalones. Esto algunos lo dicen. Y yo explico a las mujeres que los vaqueros, los pantalones son bastante populares en Rusia, pero yo aconsejo siempre para la primera entrevista llevar la falda, porque parece que para el hombre es muy importante, ver las piernas, ver el cuerpo y sentirse con una mujer femenina.
\end{abstract}

Finalmente debemos hacer mención a las motivaciones de índole material. La razón que el entorno social español percibe mayoritariamente como la causa principal de que una mujer de las procedencias estudiadas se decida por conseguir una relación de pareja con un español, como dijimos, es su deseo de huir de la precariedad, y en algunos casos de la miseria, de su país y, asimismo conseguir los "papeles" de la nacionalidad española, para mejorar su vida, la de sus hijos e incluso la de su entorno familiar. Los dos fragmentos que siguen, de una novela española galardonada y publicada en 2006 el primero, y de una novela cubana de 1998, pero publicada también en 2006 en España, son una buena muestra de este sentir generalizado:

\footnotetext{
${ }^{10}$ Nótese la transición brusca entre la reproducción del discurso de los hombres españoles y la incorporación súbita de la primera persona, continuando el mismo argumento.
} 
- ¿Que te deje? Si eres un niño chico, si no te das cuenta de que ella lo único que quiere son los papeles y en cuanto los tenga te confesará que tiene cinco hijos y conociéndote te convencerá para meterlos en tu casa y cuando ya te haya sangrado todo lo posible te mandará a tomar por culo, que las rusas son así, y antes de mandarte a tomar por culo te dirá que además es que anda por aquí su antiguo marido que también es ruso y tiene unos brazos así de boxeador y que como te descuides te abrirá la cabeza.

- Pero qué dices, Rafa. Que me dejes.

(P. Aranda, Ucrania).

- Ay, si este imbécil se casara conmigo y me llevara de aquí (...)

- Ah, chica, no jodas. ¿Cómo te vas a casar con ese muchacho? ¿Tú no ves que es un inútil, medio bobo?

- No sabe ni templar, pero yo lo enseño. Lo malo es que tiene una pinguita chiquita. Ni me la siento. Pero no importa. Ya me dijo que quiere casarse. ¡Está arrebatao!

- ¿Qué tú le hicistes, mamita?

— Lo volví loco. Me lo templé por todos lados.

(P. J. Gutiérrez, Trilogía sucia de La Habana).

En ambos casos la mujer extranjera deseosa de casarse con un español es incluida en el selecto grupo de sospechosas habituales, en tanto que el hombre español es presentado como una víctima inocente seducida por las artimañas arteras de la belleza y el sexo utilizados con fines espurios. Una informante perteneciente al entorno familiar de un hombre unido sentimentalmente a una mujer extranjera nos acaba de dibujar, con crudeza y sin ambages, el cuadro de la representación socialmente hegemónica de las uniones mixtas:

Mi criterio es: ¿quién conecta con mujeres rusas y latinas? Los que tienen algún problema físico o psíquico (que es el caso de su familiar), lo siento. Entonces ¿qué buscan? Una persona que saben que lo necesita y punto. Una persona que saben que lo necesita y que aquí le rechazaría [...]. Creo que la mayoría es porque tienen alguna cosa que les impide acceder por una vía normal [en contraposición a Internet]. Y después por la mitificación del concepto de las mujeres rusas que están muy buenas. Y las cubanas que sexualmente están muy bien [...] Yo creo que es más por el sexo. O sea, una cubana joven, una mujer joven y guapa y un hombre que ronda los 50 , entre 40 y 50 , es el sueño de todo hombre, una tía buena y joven y que no tiene manías de acostarse con él. El mito sexual. Yo no creo que busquen enamorarse. Bueno, si además te enamoras, pues de puta madre. Y si además te hacen la comida, pues perfecto, pero el mito es decir: acostarse y dormir con una tía buena, porque se las cogen guapas... ¿Qué miran? ¿Las cualidades o el físico? Que esté buena. Y, además, creo que es el mito de los tíos a partir de los 40 . Y además son dos modelos: la guapa elegante y la otra, la exuberante y sensual, que sexualmente nunca tienen bastante, que están más liberadas, todo el modelo latinoamericano. Pero quizá todo esto lo pienso como mujer, que es que creo que los hombres tienen siempre más presente el sexo que las mujeres (Nike, española, 41 años, casada con español). 
En tales representaciones se expresa, creemos, el rechazo a lo que supone una transgresión de la norma homogámica y la incapacidad de una sociedad para aceptar la heterogamia, puesto que las uniones mixtas son percibidas por lo general como claramente hipergámicas para el cónyuge extranjero e hipogámicas para el cónyuge español.

Ya hemos apuntado que valorar las ventajas de la sociedad a la que emigran es un hecho que normalmente es admitido por estas mujeres, pero en buena parte de los casos se apresuran a desmentir la exclusividad de tal expectativa; por una parte, como también hemos señalado, para desmarcarse de una imagen negativa dominada por razones económicas, y, por otro lado, debemos destacar que para muchas de nuestras informantes su migración les ha supuesto establecerse en un nivel económico y social inferior a aquél del que partían, por lo que han acabado realizando un matrimonio hipogámico. Mujeres con formación, alto nivel cultural, trabajo y una posición social destacada en su país han cambiado no sólo de país sino de estatus, puesto que en la sociedad receptora no han podido desarrollar todas sus capacidades, encontrar un trabajo de un nivel parecido al que tenían en su país, convalidar sus estudios académicos, etc. En este sentido es preciso considerar el importante papel que juega la economía política en estas relaciones y en las ideologías de género que promueven la atracción y el deseo por los hombres occidentales y por las mujeres de determinadas regiones del mundo.

Si bien las aspiraciones de mejora material, condensadas en la expresión claramente peyorativa del matrimonio por interés, han alimentado un ejercicio metonímico para gran parte de la opinión pública, que centra la mirada sobre las parejas mixtas en este punto exclusivamente, y han favorecido también la actitud reactiva de muchos de los afectados, lo cierto es que la realidad, en ocasiones, se aleja de cualquier atisbo de maquinación perversa e intereses espurios para ubicarse en el plano de la naturalidad y el pragmatismo más prosaicos. El caso de Tania es un buen ejemplo de ello:

Él me ofreció vivir en su casa a cambio de compañía, un poco de orden y estabilidad. Me dijo que me quería ayudar. Me explicó que vivía solo, que su ex pareja lo abandonó hacía un par de años y que se le hacía la casa grande. Me dijo: 'Si te portas bien y cuidas mi casa... si te comportas fuera de mi casa y dentro, o, si no, no empezamos nada'. [...] Yo pensé más vale tener a una persona y estar protegida que ser una mujer de fuera y sola. Al cabo de un tiempo pude traer a mis hijos desde Rusia y él les ha hecho de padre. Cuando llegaron incluso les quería dar su apellido. Él sólo quería una mujer legal [...]. Yo le digo a los niños que este es el padre hasta que nos morimos... o al menos hasta que yo muera (Tania, moldava, 36 años; español, 52 años). 
En esta consideración de las dimensiones materiales - por otra parte presentes en cualquier tipo de unión sentimental ${ }^{11}$ - relativas a la parte extranjera de las parejas mixtas radica, como se apuntó, buena parte del discurso social que las estigmatiza con expresiones tales como matrimonios por interés, blancos o de conveniencia.

En el re-juego constante y contrastante, en fin, de motivos y razones intervinientes en la uniones mixtas expresadas por la pluralidad de voces que hemos ido convocando, tal vez hay un motivo, el que en cualquier otro tipo de unión protagonizada por individuos de la misma nacionalidad no se plantearía ni cuestionaría y se daría por sentado, que en nuestro caso hemos constatado que resulta difícil de explicar, porque incomoda, por parte de los informantes y de analizar, por la nuestra, que es el tema del amor. Hemos comprobado que las mujeres nos han hablado de amor mucho más que los hombres, pero también algunos de ellos se han referido al sentimiento romántico que les ha motivado, especialmente los más jóvenes, como Igor:

Quedamos en Praga y, debido a que sentíamos, sin saberlo, esa sensación de que todo sería perfecto, allí nos conocimos y fue fascinante, fue increíble, maravilloso... Fue vernos y enamorarnos al estilo flechazo, fue vernos y no tener ni siquiera que entablar palabra para saber que aquello era incré́ble, en aquel sitio, aquella nueva, para nosotros, y maravillosa ciudad, aquellos paseos en carroza por toda Praga... bueno, compartimos mucho, hablamos mucho y parecía que aquello no era real [...]. Cuando nos fuimos lloramos mucho y en aquel momento sentimos ambos una sensación extraña en el corazón, algo que no se siente cuando se despide a una persona, sino algo como que esta persona es la mujer de mi vida, o el hombre de mi vida, algo que nunca antes con ninguna chica en la misma situación me pasó (Igor, español, 26 años; ucraniana, 24 años).

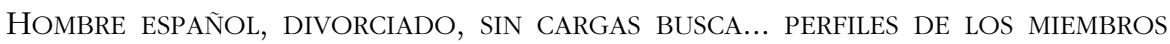
DE PAREJAS MIXTAS

Este tipo de consideraciones presentadas hasta aquí configuran el perfil de un hombre a la búsqueda de una compañera que desarrolle el rol tradicional de ama de casa. El modelo de referencia, en este caso, es el de la estricta y perfecta segregación de esferas por razón de género: la privada y reproductiva como refugio de la mujer y la pública y productiva como campo de actuación privilegiado del hombre. Una estructura de este tipo no sólo

\footnotetext{
${ }^{11}$ Son numerosos los estudios que examinan la construcción cultural del amor en una gran diversidad de lugares geográficos y que muestran su dimensión mercantil en términos de expectativas materiales, intercambio de regalos, etc. (Véanse por ejemplo Hirsch y Wardlow 2006; Illouz 1997; Jankowiak 1995; Padilla et al. 2007).
} 
implica habilidades y capacidades específicas diferenciadas, sino también incompetencias coherentes y convenientemente proclamadas:

Los hombres solos somos unos desastres, tenemos que tener nuestro complemento. A veces cuesta encontrar el complemento, pero cuando lo has encontrado, lo has encontrado. Una mujer sola está siempre bien, pero un hombre solo es un desastre. Y falta este complemento, y a veces pues has estado en pareja y no va bien este complemento o lo que sea, pero cuando lo encuentras, es... es... es una joya (Josep Ramón, español, 39 años; casado con ucraniana, 26 años).

La cita que reproducimos a continuación, correspondiente a Narcís, un español unido a una brasileña 23 años más joven, abunda en cierto modo en esta consideración y, a su vez, incorpora dos elementos nuevos interesantes de tener en cuenta:

Con mi mejor amigo dijimos que, cuando llegáramos a los 40, haríamos algo, porque cuando llegas a una edad así la soledad es mala [...].Yo cumplí 40 años y pensé que si tenía que hacer algo, debía hacerlo ya y pensé que no tenía nada que perder si me la traía aquí para probar a ver qué (Narcís, español, 43 años; casado con brasileña, 20 años).

Se trata, en mi opinión, de un planteamiento híbrido, por otro lado muy característico de la llamada post-modernidad (véase Lyon 1994²), que conjuga principios del sistema tradicional de género, hegemónico en España hasta hace unas décadas y referencia más o menos explícita y actualizada de parte del colectivo de hombres que desean una esposa de determinadas nacionalidades extranjeras, con elementos del actual desarrollo de la experiencia amorosa. En efecto, Narcís y su amigo entienden que la soltería es el mejor estado para el hombre hasta los cuarenta. Ellos no sienten la presión equivalente a la de la maternidad ni el estigma de la soltería, y desean librarse de la opresión de una relación monógama. Se trata, sin duda, de una reedición con pequeñas modificaciones del doble código de moralidad masculina característico del sistema de género tradicional (véase Roca 1996). Ahora bien, los cuarenta señalan la edad de sentar la cabeza, de vacunarse contra el peligro acechante de la soledad. Si además, como es el caso, se puede encontrar una compañera veinte años más joven la jugada se entiende perfecta. Pero eso no es todo. La actual emergencia del llamado amor confluente, sustentado en la reflexividad, permite iniciar una relación sin el lastre de la eternidad, sin "nada que perder". No es casual, en este sentido, que sea una autora la que vierta este diálogo en una novela de éxito sobre

${ }^{12}$ El autor establece que la postmodernidad genera de hecho tres respuestas posibles frente a la modernidad: resignación a lo postmoderno, reafirmación de lo moderno y retorno a lo premoderno (Lyon 1994: 74). 
los amores del anciano padre de la protagonista con una joven y guapa ucraniana:

Qué curioso que cuando comento este asunto de mi padre y Valentina con mis amigas todas se queden horrorizadas. Ven a un hombre vulnerable del que se están aprovechando. En cambio, todos los hombres con los que hablo, sin excepción, reaccionan con esas sonrisitas sardónicas de complicidad, esas risitas de admiración. Caramba con el chaval. Vaya éxito ligarse a esa pichoncita. Menuda suerte. Deja que se divierta un poco.

(M. Lewycka, Los amores de Nikolai).

Josep M. y Jordi, por una parte, y Narcís y su amigo, por otra, representan dos perfiles algo diferenciados dentro del colectivo de hombres españoles buscadores de una esposa extranjera, con razones causales tal vez algo diferenciadas pero con objetivos en gran parte coincidentes. Los primeros, de este modo, proceden de un matrimonio previo con una mujer española y un divorcio o separación consiguiente, en tanto que los segundos pertenecen al grupo de "solterones" empedernidos que a partir de una edad determinada sienten la necesidad de buscar pareja como solución a la soledad. En ambos casos podemos hablar de la existencia de un "fracaso" previo en la relación sentimental con una española: en un caso representado por la ruptura de la unión o matrimonio (divorcio) y en el otro por la incapacidad por llevarlo a cabo (mantenimiento de la soltería a una edad avanzada). Estos son, sin duda, los perfiles más conocidos y, ciertamente también, más habituales, pero no son los únicos.

José es el dueño y responsable de una de las primeras agencias matrimoniales especializadas en mujeres ucranianas y rusas existentes en España, fundada en 2002. Su visión, como agente especializado que ha intervenido en la gestión de numerosos viajes organizados de hombres españoles a los citados países en busca de esposa y que ha confeccionado catálogos de mujeres de estos países interesadas en encontrar un hombre extranjero como marido, nos permite contar con una mirada amplia sobre el perfil del colectivo de estos hombres y mujeres que nos han contado su experiencia en primera persona ${ }^{13}$ :

Ahora, también te puedo contar que el perfil de clientes que yo tengo, generalmente profesores de la universidad, asesores fiscales, empresarios de la construcción, inmobiliarios, empresarios, abogados. Una vez estuvo a punto de apuntarse un juez [...]. En muchos casos son personajes que están acostumbrados a una di-

${ }^{13}$ Evidentemente José, como cualquier otro informante, aporta una visión sobre el tema con posibles sesgos procedentes de la posición desde la que habla. En este caso debemos destacar un cierto interés de su parte por presentar una imagen de los usuarios de su agencia que huye de la de las personas con incapacidad manifiesta para la comunicación y con características físicas poco agraciadas. 
námica comercial muy agresiva. Es de aquellos que a golpe de teléfono: "Oye, tal, tal, tal y esto para mañana". Y aquí a una chica no le puedes decir: "Oye, tal, tal y para mañana otra vez"... ¡Chiiiiii! Es otra historia. Esto me ha pasado con varios clientes: tienen una dinámica profesional, trabajan todo el día y, cuando están descansando, piensan en lo que están trabajando, o en lo que van a hacer mañana o pasado mañana. Por otro lado, tienen una imagen social, que no les permite ir de pavoneo por según qué sitios. Entonces en un momento determinado pues prefieren hacer un viaje de turismo y trabajo a estos países y mirar de conocer a esa persona. [...] Yo me he encontrado con sorpresas. Y grandes. Por ejemplo, yo me he encontrado con clientes que han leído tanto de la historia de Rusia que parecen licenciados en historia rusa. Saben mucho. Y también me he encontrado clientes que no saben dónde está Rusia, ni Ucrania, ni saber la diferencia que hay entre la Unión Soviética, Rusia y Ucrania. Te puedo contar historias. Encontrar un cliente que dice: Ucrania, estos países bálticos tienen futuro. Hombre, precisamente Ucrania no son los países bálticos. Te puedo contar también de gente que le importa un pito dónde está Rusia y Ucrania. Sabe que hay mujeres bonitas, saben que hay mujeres muy cariñosas, sabe que lo que ha oído hablar de esas mujeres no lo va a encontrar aquí, y oye [...]. El perfil de edades de hombres yo he tenido, tengo hombres hasta de 60 años, 65 años, 70 años y también algunos yogurines de esos de veinte y pico años que no son capaces aquí de mantener un mínimo de relaciones con las chicas y también se han apuntado. Este es el perfil de clientes que yo tengo. Cuidado, me he encontrado gente con una bajísima formación, hasta el extremo de que te das cuenta de que es que no saben leer ni escribir, prácticamente. Un par de casos.

Natalia, responsable también de una agencia matrimonial, aporta una visión distinta, aunque complementaria, del perfil de los usuarios españoles: los hombres mayores responden a un perfil machista que no tiene consideración por la mujer y eso propicia, según la informante, que las mujeres españolas prefieran estar solas a diferencia de las rusas. Los usuarios más jóvenes de su agencia, en cambio, empiezan a romper este perfil, buscando parejas con las que formar y mantener conjuntamente una familia y no simplemente agenciarse una ama de casa. Natalia divide también las características de los usuarios por su procedencia: ámbito rural y ámbito urbano:

Hay un poco de todo. Me gusta trabajar, a lo mejor meto la pata, no sé, pero me gusta trabajar con la gente de la zona rural porque los veo, a estos hombres, muy masculinos, muy sanos físicamente y mentalmente y moralmente. Quizás no tienen este refinamiento, están un poco, ¡no son más brutos! sino sencillos. Pero son muy sanos, de buen corazón, buena situación económica, normalmente. Me gusta la gente de la ciudad también, pero la gente ésta, veo, hay médicos, hay hombres de negocios, hay informáticos, no sé, hay funcionarios, ¡muchos! Pero ésta gente la veo como un poco tocada, ya el ambiente, ya más de noche...

(E): ¿A la mujer rusa le gusta un hombre masculino?

Sí, un hombre, un hombre. Entonces, en este aspecto los hombres de la zona rural pueden ser más masculinos, a parte que no responden a nivel formativo, educativo, pero tienen otras cosas que las mujeres aprecian. 
El final de la cita nos invita a centrarnos ya, ahora, en las mujeres extranjeras que buscan o desean a su vez a estos hombres cuyos perfiles acabamos de presentar. Debemos señalar que por lo que se refiere a las características del sistema de género de sus países, en general puede constatarse la presencia en ellos de un marcado sistema patriarcal que si bien explica las restricciones morales de la movilidad femenina - de hecho, tradicionalmente, en estos contextos las mujeres no ha sido presionadas para emigrar, como sí ha ocurrido con los hombres (véase Dannecker 2005)-, también puede resultar un impulso precisamente para liberarse de estas restricciones y escapar de una situación opresiva (Gregorio 1998; Kofman et al. 2000). Este sistema explicaría la experiencia estigmatizada de las mujeres en el ámbito doméstico, caracterizada por la existencia de unas arraigadas y desiguales relaciones de poder que la subordinan (Soriano 2006) y, en general, el lugar que ocupan éstas respecto a los hombres de su país (y de su mismo estrato social), además del extremo machismo local caracterizado por la posesividad, la agresividad, el distanciamiento afectivo, la falta de respeto, la infidelidad, etc. (Piscitelli 2004). Tal caracterización, no obstante, constituye una generalización que si bien puede ser sostenida, como lo hacen de hecho diversos autores autóctonos, debe igualmente matizarse en cierto modo. La variable de la clase social, el origen rural o urbano e incluso regional, así como la edad, en este sentido, resultan a menudo bastante relevantes para atenuar o intensificar dicha afirmación. En cualquier caso, todo ello configurará un sistema de género de carácter marcadamente tradicional en el que el horizonte, para las mujeres, se situará principalmente en torno al matrimonio y la familia, tal como nos cuenta Sonia:

Las mujeres allí [Perú] se casan jóvenes, a los 21 ó 22, depende. Pocas son las que arriban a casarse mayores. O sea, que tú te casas a los 32 [como hizo ella con un españoll y ya eres mayor para allí ¿no? Claro, ¡si ya me decían que me quedaba solterona! (Peruana, 35 años; casada con español, 37 años).

En la otra punta de los marcos geográficos en que nos movemos, Natalia, mujer rusa de 25 años, nos hace una explicación similar, añadiendo además un rasgo que hemos tenido ocasión de comprobar en muchas de nuestras informantes, esto es, su progresiva adaptación a la mentalidad de nuestro país, la incorporación de elementos característicos del sistema de género español:

No tenía pareja y a los 21 años tampoco es normal en mi país. A ver, para aquí es normal. Aquí la gente empieza a pensar en familia a partir de los 30 años. En mi país no, es otra mentalidad. Ahora ya pienso como los españoles, pero antes yo pensaba como en mi país. Porque, claro, en mi país, si a los 18 años tú no estás casada, no tienes hijos, no sé, tú eres una amargada que no te mira nadie, 
que no se fija nadie... Es unas cosas que son increíbles. Si yo, por ejemplo ahora hablo con mi país y digo: Tengo 24 años, me preguntan: ¿Estás casada? Esto es la primera pregunta, si estás casada, no si estás trabajando y dónde...y cómo te ganas la vida, cómo vives y qué nivel tienes y todo. Es la mentalidad. Las mujeres de mi país piensan que lo mejor que pueden hacer en su vida es casarse y tener hijos [se ríe]. Esto es muy bonito y es muy bueno, pero... (Natalia, rusa, 25 años; soltera).

Cuando la maternidad, y el desarrollo del rol de ama de casa en general, es el principal objetivo el matrimonio acostumbra a realizarse a una edad temprana, como hemos visto. Además, la diferencia de edad con el cónyuge masculino no acostumbra a constituir una variable importante a tener en cuenta, puesto que, entre otras cosas, no es relevante para la procreación. Sí lo es, en cambio, la fertilidad, que se ha relacionado a menudo de manera preferente y hasta única con la mujer y cuya garantía se ha asociado de forma privilegiada con la edad, concretamente con la juventud ${ }^{14}$. En los dos países de procedencia mayoritaria de las mujeres-esposas de hombres españoles (Brasil y Rusia) se da la circunstancia, además, de que las características demográficas de su población presentan desequilibrios importantes entre el colectivo de hombres y el de mujeres, siendo este último considerablemente más numeroso. La "falta de hombres en el mercado" ha permitido realizar afirmaciones como la de la existencia de una suerte de poliginia disfrazada en Brasil (Berquó 1989, en Goldenberg 2006): el gran contingente de mujeres sin posibilidad de matrimonio daría lugar a la unión de muchas de ellas con hombres casados con otras mujeres, siendo así que para muchas de estas mujeres, no obstante, su consideración como las "otras" no constituye necesariamente un estigma - y en cualquier caso su posición, en un mercado afectivo-sexual tan adverso, está más valorizada socialmente que la de la mujer que no tiene un hombre- sino más bien una situación ventajosa, por cuanto se perciben como verdaderas compañeras a todos los niveles —afectivo, sexual, intelectual, cultural-y se contraponen a unas esposas que aparecen como aquellas que tienen un vínculo obligatorio y neurótico con el marido, resultando inclusive una inversión simbólica de significados según la cual la esposa acaba siendo la santa que acepta todo sin protestar y la puta que sólo tiene intereses materiales en relación al marido, mientras que la amante acaba desarrollando el "auténtico" papel

\footnotetext{
${ }^{14}$ Algunos autores que realizan una aproximación desde la biología, la zoología o la etología ponen mucho énfasis en este tipo de señales como elementos de atracción y de toma de decisión en la elección de pareja. La juventud, así, se significaría por ejemplo con una melena larga, en tanto que unos senos y caderas prominentes en la mujer simbolizarían igualmente su capacitación reproductiva (véase, entre otros, Buss 1996; Fisher 1994; Morris 2005).
} 
de esposa al representar únicamente el amor desinteresado y sincero, patente en su independencia económica y su ausencia de vínculos obligatorios con su amante, hasta el punto de conseguir algo extremadamente valorado en la cultura brasileña, la fidelidad de su compañero, que, aseguran muchas de la amantes, deja de tener relaciones sexuales con su esposa ${ }^{15}$ (Goldenberg 2006: 86-87). El "superávit" de mujeres, por su parte, habría contribuido de forma perversa a fomentar en muchos hombres la falta de sensibilidad y romanticismo, la no necesidad de esfuerzo por conseguir una mujer.

Natalia, nuestra informante responsable de una agencia matrimonial, apunta a este desequilibrio demográfico, en este caso en la antigua URSS, y añade, asimismo, algunas de las características ya señaladas de la masculinidad de los países de la ex Unión Soviética, convertidas igualmente en causas de búsqueda de un marido extranjero:

También veo, eso desde mi punto de vista particular, yo creo que en Rusia hay un problema ahora, quizás está un poco borrándose este problema, pero a mi generación y la anterior y posterior, Rusia, la URSS antigua, está y sigue siendo 30 años de guerra: hablando de la guerra de Afganistán: ¿qué tenemos? Muchos chicos murieron en la guerra de Afganistán, Nagorno-Karabak, Chechenia, muchos que han vuelto nos daban miedo! Les pasaba lo que les pasa ahora, ayer vi en la tele, están hablando de los soldados americanos que vuelven de guerra de Irak y después se suicidan. Este problema nos daba un poco de miedo. También, no voy a decir maravillas, también hay el problema de alcohol en Rusia, también con la perestroika que muchos hombres perdieron trabajo, alcohol y drogas, pues yo creo que hace dos años, hace dos si no me equivoco, las estadísticas en Rusia eran así: 10 mujeres, 5 hombres. Entonces con esta estadística, claro que la mujer tiene unas posibilidades muy reducidas para formar una familia, lo que ella le gustaría. Algunas se conforman siendo madres solteras, otras dicen "tengo mi trabajo y voy aprovechar mi juventud hasta que pueda y después dios dirá!" otras que no son tan atrevidas entonces dicen "bueno, me quedo como quedo" algunas se quedan en casa, otras se buscan una salida.

Retomando el argumento de la diferencia de edad, José, el responsable de la agencia matrimonial especializada en mujeres rusas y ucranianas, ex-

15 Obviamente esta caracterización correspondería al tercer tipo en que clasifica las "Outras" M. Goldenberg (2006: 63), el de las de más de 50 años que viven la situación de "otra" como permanente, sin expectativa de convertirse en mujeres "legítimas" de sus amantes y de que ellos se separen de sus esposas. Los otros dos tipos harían referencia a las "otras" de carácter pasajero, que serían las más jóvenes y se caracterizarían por la inexistencia de un proyecto de matrimonio: la mujer busca únicamente enamorar a su compañero y no se preocupa por la continuidad de la relación; y las "otras" de carácter transitorio, mujeres cercanas a los 40 años que luchan para conseguir una relación integral con su amante, deseando convertirse en esposas oficiales. 
pone la que a su juicio constituye la razón de la heterogamia de edad que el imaginario colectivo atribuye a las parejas mixtas:

Sí. Sí, les da igual, pero vuelvo a lo de antes, que prefieren estar subordinadas, aceptan esta subordinación siempre y cuando que: ¿đónde está la madurez de un hombre? En la edad. Para aguantar hombres jóvenes inmaduros ya los tienen allí. Allí también se casan con una diferencia de edad grande y no les importa ${ }^{16}$. Buscan un hombre que les dé estabilidad emocional, que les dé cariño, que les dé una familia, y ya se entiende que si afuera tienen que aceptar edades, que sean diferencias de edad grandes, no les importa.

Los propios protagonistas parecen ser conscientes de esta característica y aportan datos al respecto:

La mía tiene 21 y está conmigo, que tengo 34. Otra [pareja de un amigo] tiene 27 y está con uno de casi 50. Aquí una de 27 se buscaría uno más joven. Eso está claro. Aquí sería mucho más complicado encontrar una chica así, con esta diferencia de edad (Cisco, español, 34 años; novio de cubana, 21 años).

Volviendo a la caracterización del colectivo de mujeres no españolas ni de la Europa Comunitaria que desean encontrar un hombre de estas nacionalidades, nos encontramos con que el perfil mayoritario parece bastante delimitado. Natalie, directora de la agencia Natali, en Kiev, nos explicaba que el perfil de las 50 chicas inscritas en su agencia era el siguiente: el $60 \%$ tiene menos de 30 años, el 30\% tiene hijos, el 30\% sabe alguna lengua extranjera (generalmente inglés), el 85\% tiene estudios universitarios, y el $80 \%$ es de Kiev. Sus preferencias, a su vez, parecen claras y sencillas: hombres europeos, aunque algunas manifiestan no querer ir a Alemania ${ }^{17}$ y otras no desean ir a EE.UU., porque piensan que la personalidad de los hombres de allí es muy extraña. Los datos coinciden con los que pudimos constatar en la agencia que utilizamos en nuestro viaje a Kiev y que aparecían en su página web: en abril de 2007 esta agencia tenía 1.020 chicas publicitadas, con una o diversas fotos y su correspondiente perfil, mayoritariamente de Kiev. Aparecían agrupadas por franjas de edad, siendo la de 25 a 30 años la más numerosa (con 300 mujeres) ${ }^{18}$. Como ya observó Ara Wilson muy

${ }^{16}$ Tal vez sería más preciso decir que lo tienen asumido. Natalia, una ucraniana divorciada de 51 años, inscrita en una agencia matrimonial de Kiev, nos manifestó su frustración por el hecho que señores mucho mayores que ella buscaran mujeres mucho más jóvenes que ella. La calle (se refiere a Kiev), nos dijo en su inglés precario, está llena de chicas jóvenes disponibles.

${ }^{17}$ Algo que pude constatar también en primera persona en Kiev. Elvira, de 35 años, divorciada y con tres carreras universitarias (filología, intérprete y química) afirmó negarse a quedar y hablar con alemanes.

${ }^{18}$ El resto de franjas de edad eran: menos de 25 años, de 31 a 35 años y más de 36 años. 
precozmente (1988) estos catálogos promueven, probablemente, una cosificación voyeurística de estas mujeres como "otras" en contraste con las feministas occidentales liberadas.

\section{CONCLUSIONES: MÁS ALLÁ DEL ESTEREOTIPO Y LA SIMPLIFICACIÓN}

En este artículo nos hemos centrado en el abordaje del fenómeno de las llamadas parejas, uniones o matrimonios mixtos, binacionales o transnacionales. Siempre han existido parejas cuyos cónyuges pertenecen a nacionalidades distintas, pero debemos reconocer que desde la década anterior hasta la actualidad esta realidad ha alcanzado una dimensión sin precedentes. Las razones de tal crecimiento las encontramos en la generalización de la movilidad de las personas, más allá de los procesos migratorios clásicos, facilitada por un desarrollo extraordinario de las tecnologías de la información y de la comunicación y por un cambio de paradigma, a nivel superestructural, en relación al concepto de amor y a la naturaleza de las relaciones de género, dentro del marco más amplio de redefinición de los proyectos biográficos. En España la emergencia de parejas mixtas ha tenido una especial relevancia por la posición destacada que ha ocupado el país como destino migratorio y como centro de importantes transformaciones en su sistema de género.

Dentro de la diversidad de aspectos que suscitan las denominadas parejas mixtas hemos privilegiado la cuestión de las motivaciones que hombres y mujeres — sólo hemos tenido en cuenta parejas mixtas heterosexuales - pertenecientes a este tipo de uniones manifiestan tener para llevarlas a cabo. La etnografía que hemos realizado nos ha mostrado la pluralidad de razones y de experiencias diferenciadas que se entretejen en el campo de los amores mixtos y nos ha permitido, por tanto, ir más allá de la simplificación, basada poco más que en el tópico, el estereotipo y el prejuicio, que a menudo domina en la opinión pública y los medios de comunicación. Los matrimonios mixtos, en este sentido, no pueden ser vistos como un simple movimiento unidireccional del Este al Oeste o del Sur al Norte, fundado en el deseo de pasar de la opresión a la liberación, de lo tradicional a lo moderno, o de lo local a lo global, si bien algunos hombres y mujeres pueden percibirlos así en algún momento. Como ha señalado con acierto Nicole Constable (2003: 177) tales dicotomías oscurecen la complejidad de los circuitos entrelazados por una red de experiencias diversas. Podemos encontrar casos, como hemos visto, de motivaciones sustentadas en una fuerte conciencia de "liberación" por parte de las mujeres que migran para formar una pareja mixta, respecto a relaciones de género opresivas, y 
también una voluntad de mejora de las condiciones de vida, con independencia que luego se puedan producir nuevas "opresiones" en forma de reclusión en el hogar y dificultades para acceder a la esfera pública. Entre los hombres españoles, por su parte, la búsqueda de una mujer que suponen más tradicional, que prioriza el hogar y la familia y acepta una posición de cierta subordinación hacia el marido, parece constituir el paradigma dominante, conectado además a una cierta lógica neo-colonial de poder y dominación. Está claro, no obstante, que las razones para una búsqueda de este modelo de compañera tienen un origen diverso que va de la frustración y resistencia ante los avances protagonizados por las mujeres españolas a simplemente una oportunidad más para encontrar pareja dentro de un supermercado sentimental que se ha visto ampliado considerablemente en los últimos años. Resulta claro también, en este caso, que las expectativas y deseos no son garantía necesariamente de éxito y muchas de estas esposas extranjeras de parejas mixtas con hombres españoles van a seguir un proceso de emancipación similar al protagonizado por muchas mujeres españolas. En cualquier caso, además, los diversos estadios del proceso de constitución de una pareja mixta, del que hemos profundizado apenas aquí el primero, muestran a unas mujeres y unos hombres que toman la iniciativa, que realizan elecciones y que devienen agentes activos, lo cual no niega que no estén sometidos a la influencia de los respectivos sistemas e ideologías de género y a factores sociales, estructurales y culturales. Y todo ello no significa necesariamente, además, que el amor y la emoción estén ausentes o carezcan de importancia. A menudo, en este sentido, la mirada académica y de activistas de distintas causas sobre esta realidad se ha apuntado a la narrativa del rescate que percibe a las mujeres no occidentales que se unen a maridos occidentales como pobres víctimas necesitadas de ayuda y protección, como mujeres oprimidas y traficadas que deben ser rescatadas, en lo que acaba siendo una suerte de colonización discursiva.

Los matrimonios binacionales, especialmente aquellos que preceden al proceso migratorio de una de las partes, nos obligan a repensar y reelaborar los conceptos de tradición y modernidad, articulados de nuevas y contradictorias maneras. El Oeste, el Norte, no es simplemente el lugar de liberación, aunque pueda imaginarse como tal para muchas personas. Representa e implica, asimismo, la posibilidad de nuevas subjetividades, nuevas formas de poder, nuevas opresiones y también de nuevas oportunidades.

\section{BIBLIOGRAFÍA CITADA}

Appadurai, A. 2001. La modernidad desbordada. Buenos Aires: FCE. Aranda, P. 2006. Ucrania. Barcelona: Destino. 
Barbara, A. 1985. Marriages sans frontières. París: Les Centurión.

Bauman, Z. 1992. Intimations of Postmodernity. Londres-Nueva York: Routledge.

Beck, U., A. Giddens y S. Lash. 1994. Reflexive modernization. Stanford: Stanford University Press.

Beck. U. y E. Beck-Gernsheim. 1998. El normal caos del amor. Barcelona: Roure.

Bermúdez, E. M. 2007. Historias de unión y de amor en parejas mixtas que residen en la Comunidad Valenciana: relatos desde la masculinidad y la feminidad. Barcelona: CeiMigra, Bancaja.

Buss, D. M. 1996 La evolución del deseo. Madrid: Alianza.

Cahill, D. 1990. Intermarriages in International Contexts: A Study of Filipina Women Married to Australian, Japanese, and Swiss Men. Quezon City: Scalabrini Research Center.

Chin, K. 1994. "Out-of-Town Brides: International Marriage and Wife Abuse among Chines Immigrants". Journal of Comparative Family Studies 25 (1): 53-71.

Clark, C. 2001. "Foreign Marriage 'Tradition' and the Politics of Border Crossings", en N. Chen et al. (eds), China Urban: Ethnographies of Contemporary Culture: 104-122. Durham: Duke University Press.

Cohen, E. 1986. "Lovelorn Farangs: The Correspondence between Foreign Men and Thai Girls". Anthropological Quarterly 59 (3): 115-128.

Constable, N. (ed.). 1998. Cross-Border Marriages: Gender and Mobility in Transnational Asia. Filadelfia: Pennsylvania University Press.

Constable, N. 2003. Romance on a Global Stage. Berkeley: University of California Press.

Cooke, F. M. 1986. Australian-Filipino Marriages in the 1980s. Queensland: Griffith University Press.

Dannecker, P. 2005. "Transnational Migration and the Transformation of Gender Relations: the Case of Bangladeshi Labour Migrants". Current Sociology 53 (4): 655-674.

De Melo, R. 2000. "Vivendo um Conto de Fadas: O imaginário de gênero entre cariocas e estrangeiros", en M. Goldenberg (org.), Os Novos Desejos: 147-183. Río de Janeiro: Record.

Delcroix, C. y A. Guyaux. 1992. Double mixte. París: L'Harmattan.

Featherstone, M. (ed.). 1990. Global Culture. Nationalism, Globalization and Modernity. Londres: Sage.

Featherstone, M. 1991. Consumer Culture \& Postmodernism. Londres: Sage.

Fisher, H. E. 1994. Anatomía del Amor. Barcelona: Anagrama.

Gamburd, M. 2000. The Kitchen Spoon's Handle: Transnationalism and Sri Lanks's Migrant Housemaids. Ithaca, Nueva York: Cornell University Press.

García Canclini, N. 1995. Consumidores y ciudadanos. México: Grijalbo.

Giddens, A. 2000a. La transformación de la intimidad. Madrid: Cátedra.

Giddens, A. 2000b. Un mundo desbocado. Madrid: Taurus.

Gil Calvo, E. 1997. El nuevo sexo débil. Madrid: Temas de Hoy.

Goldenberg, M. 2006. Infiel: notas de uma antropóloga. Río de Janeiro-Sâo Paulo: Record.

Gregorio, C. 1998. Migración femenina. Su impacto en las relaciones de género. Madrid: Narcea.

Gutiérrez, P. J. 2006. Trilogía sucia de La Habana. Barcelona: Anagrama.

Halualani, R. 1995. "The Intersecting Hegemonic Discourses of an Asian Mail-Order Bride Catalog: Filipina 'Oriental Butterfly' Dolls for Sale”. Women's Studies in Communication 118 (1): 45-64. 
Hannerz, U. 1998. Conexiones transnacionales. Madrid: Cátedra.

Hirsch, JS y H. Wardlow (eds.). 2006. Modern Loves: The Anthropology of Romantic Courtship and Companionate Marriage. Ann Arbor: University of Michigan Press.

Illouz, E. 1997. Consuming the romantic utopia. Berkeley: University of California Press.

Jankowiak, W. (ed.). 1995. Romantic Passion: A Universal Experience?. Nueva York: Columbia University Press.

Johnson, E. 2007. Dreaming of a Mail Order Husband: Russian-American Internet Romance. Durham: Duke University Press.

Johnson-Hanks, J. 2007. "Women on the market: marriage, consumption, and the Internet in urban Cameroon". American Ethnologist 34: 642-58.

Kofman, E. et al. (eds.). 2000. Gender and International Migration in Europe. Employment, Welfare and Politics. Londres: Routledge.

Lewycka, M. 2006. Los amores de Nikolai, Barcelona: Lumen.

Lyon, D. 1994. Postmodernity. Minneapolis: University of Minnesota Press.

Mac an Ghaill, M. (ed.). 1996. Understanding Masculinities. Filadelfia: Open University Press.

Maclnnes, J. 1998. The End of Masculinity. Filadelfia: Open University Press.

Mainardi, G. 2006. Miroirs migratoires. Entre le Brésil et la Suisse: vécus de femmes brésiliennes. Berna: Peter Lang.

Morris, D. 2005. La mujer desnuda. Barcelona: Planeta.

Ordóñez, R. 1997. "Mail-Order Brides: An Emerging Community", en M. P. Root (ed.), Filipino Americans: Transformation and Identity: 121-142. Thousand Oaks: Sage Publications.

Padilla, M. et al. (eds.) 2007. Love and Globalization: Transformations of Intimacy in the Contemporary World. Nashville: Vanderbilt University Press.

Parreñas, R. 2005. Children of Global Migration: Transnational Families and Gendered Woes. Stanford: Stanford University Press.

Piper, N y M. Roces (eds.). 2003. Wife or Worker? Asian Women and Migration. Nueva York: Rowman \& Littlefield.

Piscitelli, A. 2004. "El tráfico del deseo: interseccionalidades no marco do turismo sexual no Nordeste do Brasil". Quaderns de l'Institut Català d'Antropologia 4:1-16.

Riaño, Y. 2003. "Migration of Skilled Latin American Women to Switzerland and Their Struggle for Integration", en M. Yamada (ed.), Latin American Emigration: Interregional Comparison among North America, Europe and Japan: 33-343. Population Movement in the Modern World VII. JCAS Symposium Series 19. Osaka: National Museum of Ethnology.

Riaño, Y. y N. Baghdadi 2007. "Je pensais que je pourrais avoir une relation plus égalitaire avec un Européen'. Le rôle du genre et de l'imaginaire géographique dans la migration des femmes". Nouvelles Questions Féministes 26 (1): 38-53.

Robertson, R. 1992. Globalization, Social Theory and Global Culture. Londres: Sage.

Robinson, K. 1996. "Of Mail-Order Brides and 'Boys Own' Tales: Representations of AsianAustralian Marriages". Feminist Review 52: 53-68.

Roca, J. 1996. De la pureza a la maternidad. Madrid: Ministerio de Educación y Cultura.

Roca, J. 2009. "Migraciones amorosas. Migraciones (re)negadas". Revista Migraciones 25: 89-124.

Roca, J. et al. 2009. "Amor importado, migrantes por amor: la constitución de parejas entre españoles y mujeres de América Latina y de Europa del Este en el marco de la 
transformación actual del sistema de género en España”. En http://www.inmujer. migualdad.es/mujer/mujeres/estud inves/766.pdf.

Sahlins, M. 1977. Economía de la Edad de Piedra. Madrid: Akal.

Scholes, R. 1999. The Mail Order Bride Industry and Its Impact on Immigration, en International Matchmaking Organizations: A Report to Congress (Appendix A). Disponible en: http://www.ins.usdoj.gov/graphics/aboutins/repsstudies.Mobrept full.pdf.

Seidler, V. J. 2006. Masculinidades. Culturas globales y vidas intimas. Barcelona: Montesinos.

Shumway, D. R. 2003. Modern Love: Romance, Intimacy and the Marriage Crisis. New York: N. Y. Univ. Press.

Simmons, L. A. 1999. "Mail Order Brides: The Legal Framework and Possibilities for Change", en G. A. Kelson y D. DeLaet (eds.), Gender and Immigration: 127-143. Nueva York: N. Y. University Press.

Soriano, R. M. 2006. "Voces de mujeres desde la inmigración: una comparativa entre el asentamiento de marroquíes en España y mexicanas en EE.UU". The Center for Comparative Immigration Studies. San Diego: University of California. Disponible en: http://www.ccis-ucsd.org/publications/wrkg133.pdf

Suzuki, N. 2003. Battlefields of Affection: Gender, Global Desires and the Politics of Intimacy in Filpina-Japanese Transnational Marriages. Tesis Doctoral. Dept. Anthropology. Manoa: Univ. of Hawaii.

Thai, H. C. 2008. For Better or Worse: Vietnamese International Marriage in the New Global Economy. New Brusnwick: Rutgers University Press.

Théry, I. 1998. Couple, filiation et parenté aujourd'bui. Le droit face aux mutations de la famille de la vie privée. París: Odile Jacob.

Wang, H. C. y S. M. Chang 2002. "The commodification of international marriages: crossborder marriage business between Taiwan and Viet Nam". International Migrations 40: 93-116.

Wilson, A. 1988. "American Catalogues of American Brides", en J. Cole (ed.), Anthropology for the Nineties: 114-125. Nueva York: Free Press.

Wimmer, A. 1998. "Zurich's Miami. Transethnic relations of a transnational community". Transnational Communities working paper series WPTC-98-07. University of Oxford. Disponible en: http://www.transcomm.ox.ac.uk/working papers.htm

Zelizer, V. A. 2005. The Purchase of intimacy. Princeton: Princeton University Press.

Fecha de recepción: 13 de enero de 2011

Fecha de aceptación: 29 de julio de 2011 